\title{
Does steroid pulsing influence the efficacy and toxicity of chrysotherapy? A double blind, placebo controlled study
}

C S Wong, G Champion, M D Smith, M Soden, $M$ Wetherall, R A Geddes, W R Hill, M J Ahern, P J Roberts-Thomson

\begin{abstract}
To test the hypothesis that early steroid pulsing augments the efficacy and decreases the toxicity of chrysotherapy $\mathbf{4 0}$ patients with rheumatoid arthritis were studied in a double blind, placebo controlled study. During the first three months of gold treatment group 1 received monthly intravenous methylprednisolone pulsing (steroid group) while group 2 received placebo (placebo group). All patients were assessed clinically and serologically over a 24 week period. Twelve patients were withdrawn before completion of the study and all but one of the remaining 28 patients reported clinical and serological improvements. Two patients in the steroid group were withdrawn owing to gold induced side effects while four were withdrawn in the placebo group. These small numbers were not significantly different. Minor side effects occurred more commonly in the placebo group. The clinical response was clearly better in the steroid group with statistical significance almost being achieved. In an endeavour to obtain a significant conclusion further patients will now be entered into this study.
\end{abstract}

Chrysotherapy has long been established as an effective treatment in suppressing disease activity in rheumatoid arthritis. Treatment is usually given as weekly intramuscular injection of gold salts. Most studies report useful therapeutic response in two thirds of patients, with $10-20 \%$ patients achieving almost complete remission generally apparent by the 12 th week of treatment. ${ }^{1}$ The duration of suppressive response is variable. One third of patients receiving gold develop gold related side effects, however, and treatment is withdrawn in half of this population. ${ }^{12}$

Intravenous pulsing with large doses of methylprednisolone at monthly intervals has been shown to result in dramatic alleviation of articular symptoms in rheumatoid arthritis. ${ }^{34}$ The duration of response is short lived, however, and does not significantly retard progression of the disease. This regimen has advantages over the continuous administration of oral steroids as serious side effects seem to be less common.

During an open pilot study in which intravenous methylprednisolone pulsing was undertaken at the time of initiation of chrysotherapy we were impressed with the early clinical responses and the lack of gold related side effects in our group of rheumatoid patients. ${ }^{5}$
These observations raised the possibilities that steroid pulsing 'primed' the patients to respond to gold as well as reducing toxicity.

We report the results for 40 patients with active rheumatoid arthritis who were randomly allocated either to receive pulsed methylprednisolone and gold (sodium aurothiomalate) treatment (group 1) or pulsed placebo infusion and gold treatment (group 2). All patients were monitored clinically and with laboratory assessments.

\section{Patients and methods}

Over a 27 month period 40 patients with classical or definite rheumatoid arthritis defined by American Rheumatism Association criteria were included in the study. All patients had active rheumatoid arthritis defined as more than three swollen joints, morning stiffness of greater than 45 minutes' duration, and a raised erythrocyte sedimentation rate or $C$ reactive protein. They had been treated with optimal doses of non-steroidal anti-inflammatory drugs and had moderate or marked restriction of function, thus justifying second line drug treatment.

Informed consent was obtained from all patients. There was no evidence of hepatic, haematological, or renal disease, and patients with insulin dependent diabetes mellitus were excluded.

All patients received intramuscular sodium aurothiomalate according to a standard protocol used in our department. The initial dose was 10 $\mathrm{mg}$ as a precaution for any immediate hypersensitivity reaction, the second dose was $20 \mathrm{mg}$ given one week later, the third dose $50 \mathrm{mg}$ in the third week, and thereafter $50 \mathrm{mg}$ weekly. Treatment with non-steroidal anti-inflammatory drugs and analgesic drugs was continued unchanged throughout the study. Intra-articular corticosteroids were not permitted during the trial or within four weeks of entry into the trial.

These 40 patients were randomly allocated to either one of two groups.

Three intravenous pulses of $1.0 \mathrm{~g}$ methylprednisolone in $100 \mathrm{ml}$ normal saline were given over 30 minutes at time 0,4 , and 8 weeks to 20 patients in group 1 , while 20 patients in group 2 received $100 \mathrm{ml}$ saline infusion at the same intervals. These intravenous infusions were prepared by a pharmacist and both the patients and observer were unaware of the nature of the infusion. A second independent observer, who was aware of the nature of the infusion, assessed any potential drug toxicity by reviewing patients' progress at weeks $0,1,2,3,4,6,8$, $12,16,20$, and 24 
Clinical assessment was based on a visual analogue score for pain (maximum 30), visual analogue score for morning stiffness (maximum 30 ), doctor's assessment (maximum 30), and the Ritchie joint index (maximum 78), total maximum clinical score being 168. These were measured by the same 'blinded' observer on entry to the study and at weeks $12,16,20$, and 24. Assessments before week 12 were not performed as they would threaten 'blindness'. Good responders were classified by $>50 \%$ reduction in clinical score over the 24 week period, partial responders by $>20 \%$ but $<50 \%$ reduction, and non-responders by $<20 \%$ reduction in clinical score.

Complete blood picture analysis and urine analysis for blood and protein were performed on entry and at weeks $1,2,3,4,6,8,12,16,20$, and 24 . Immune indices were assessed on entry and at weeks $4,8,12,16$, and 24 . These included rheumatoid factor (Beckman ICS using rate nephelometry), immunoglobulins, immune complexes, and $\mathrm{C}$ reactive protein. On all occasions blood was obtained before any intramuscular injection of gold.

Patients were interviewed for possible side effects at weeks $2,4,8,12,16,20$, and 24 . Thrombocytopenia was defined as a platelet count below $150 \times 10^{9} / 1$ and leucopenia was defined as a total white cell count below $3.5 \times 10^{9} / 1$, or neutrophil count below $1 \cdot 5 \times 10^{9} / 1$. Proteinuria of $>2+$ on dipstick urine analysis was followed by 24 hour measurement and $0.5 \mathrm{~g} / 24 \mathrm{~h}$, or more, was considered significant. Withdrawal criteria included thrombocytopenia, leucopenia, drug fever, significant rash, significant diarrhoea of greater than four loose bowel motions a day, mucositis, or significant proteinuria. Patients could also be withdrawn if there was increased severity of arthritis after three months of treatment.

\section{STATISTICAL ANALYSIS}

We used the statistical package for the social sciences (SPSS-X) on the Flinders University of South Australia Encore Multimax computer running operating system UNIX BSD4.2. Except for the $\chi^{2}$ test, data were log transformed and analysed using multiple analysis of variance. Statistical significance was accepted at the $5 \%$ level $(p=0 \cdot 05)$.

\section{Results}

Table 1 lists the demographic details of the patients enrolled in the study.

Twenty eight of the 40 patients completed the study. Five patients from group 1 withdrew

Table 1: Demographic details of patient groups

\begin{tabular}{|c|c|c|c|}
\hline Group ${ }^{*}$ & Sext & $\begin{array}{l}\text { Mean age } \\
\text { (years) }\end{array}$ & $\begin{array}{l}\text { Mean duration } \\
\text { of disease } \\
\text { (range) } \\
\text { (months) }\end{array}$ \\
\hline$\frac{1}{2}$ & $\begin{array}{l}11 M, 9 F \\
14 M, 6 F\end{array}$ & $\begin{array}{ll}M=66, & F=59 \\
M=64, & F=65\end{array}$ & $\begin{array}{ll}71 & (1-420) \\
63 & (3-240)\end{array}$ \\
\hline
\end{tabular}

before completion. Two patients withdrew for non-medical reasons. Two developed a significant drug rash, one at week 8 , the other at week 20. One patient was withdrawn at week 12 owing to stomatitis. (Her stomatitis persisted and she was subsequently found to have pernicious anaemia.)

Seven patients from group 2 withdrew before completion. One failed to comply with the protocol and subsequently was found to have gastric malignancy and another died from sudden cardiac death. Two patients developed gold rash at weeks 1 and 20 respectively. One patient developed stomatitis at week 12 . One patient developed aplastic anaemia at week 4. One patient withdrew for personal reasons. All patients made a good recovery from their gold related side effects. The patient who developed gold induced aplasia was given antithymocyte globulin treatment and achieved sub-normal haematological indices, sufficient to be discharged home to a normal lifestyle.

A $\chi^{2}$ test of independence with Yates's correction was performed to compare the incidence of withdrawal due to side effects between groups 1 and 2 . This was insignificant, but the small numbers made any conclusions difficult.

Four patients in group 1 complained of minor discomforts-namely, transient arthralgia, transient depression, mild nausea, and dryness in the mouth. Among those in group 2, seven patients reported side effects: one patient developed a rash necessitating a dose reduction of gold, one developed marked eosinophilia of $27 \%$, which returned to normal after gold was stopped but did not recur on its reintroduction, one reported skin irritation with each gold injection, one had mouth ulcers, one had urticaria, one became non-specifically unwell after each intramuscular injection, and one had local drip site infection, which rapidly subsided.

All but one patient showed significant improvement in their symptoms and serological markers over the 24 week period. Among group 1 , there were 12 good responders and two partial responders. Among group 2, there were seven good responders and six partial responders. The only one poor responder belonged to group 1. Tables 2, 3, and 4 present the effects of pulsed methylprednisolone $v$ placebo by analysing the clinical scores, $\mathrm{C}$ reactive protein, and rheumatoid factor over time.

The data on clinical scores (table 2) and C reactive protein (table 3 ) are in keeping with clinical and serological trends for improvements in both groups with time. When the clinical

Table 2: Results of clinical scores in both groups. Results are shown as mean (SD) and range

\begin{tabular}{llllll}
\hline Group $^{*}$ & Week & & & \\
\cline { 2 - 6 } & 0 & 12 & 16 & 20 & 24 \\
\hline 1 & $72(20)$ & $50(24)$ & $39(14)$ & $35(16)$ & $27(16)$ \\
& $(34-125)$ & $(25-102)$ & $(15-69)$ & $(14-70)$ & $(4-59)$ \\
& $\mathbf{n}=20$ & $\mathbf{n}=16$ & $\mathbf{n}=15$ & $\mathbf{n}=15$ & $\mathbf{n}=15$ \\
2 & $68(13)$ & $41(19)$ & $33(15)$ & $37(23)$ & $28(16)$ \\
& $(41-93)$ & $(20-77)$ & $(14-64)$ & $(13-91)$ & $(0-60)$ \\
& $\mathbf{n}=20$ & $\mathbf{n}=17$ & $\mathbf{n}=15$ & $\mathbf{n}=14$ & $\mathbf{n}=13$ \\
\hline
\end{tabular}


Table 3: Results of $C$ reactive protein in both groups. Results are shown as mean (SD) and range

\begin{tabular}{|c|c|c|c|c|c|c|}
\hline \multirow[t]{2}{*}{ Group ${ }^{*}$} & \multicolumn{6}{|l|}{ Week } \\
\hline & $\overline{0}$ & 4 & 8 & 12 & 16 & 24 \\
\hline 1 & $\begin{array}{l}55(34) \\
(10-112) \\
n=20\end{array}$ & $\begin{array}{l}48(42) \\
(<6-130) \\
n=18\end{array}$ & $\begin{array}{l}36(36) \\
(<6-113) \\
n=18\end{array}$ & $\begin{array}{l}30(30) \\
(<6-111) \\
\mathrm{n}=17\end{array}$ & $\begin{array}{l}18(16) \\
(<6-67) \\
n=16\end{array}$ & $\begin{array}{l}14(10) \\
(<6-43) \\
n=15\end{array}$ \\
\hline 2 & $\begin{array}{l}52(48) \\
(<6-161) \\
n=20\end{array}$ & $\begin{array}{l}43(45) \\
(<6-165) \\
n=18\end{array}$ & $\begin{array}{l}30(32) \\
(<6-132) \\
n=19\end{array}$ & $\begin{array}{l}27(33) \\
(<6-109) \\
n=16\end{array}$ & $\begin{array}{l}21(24) \\
(<6-74) \\
n=15\end{array}$ & $\begin{array}{l}17(27) \\
(<6-106) \\
n=13\end{array}$ \\
\hline
\end{tabular}

For explanation of groups see table 1.

Average test of significance, group by time $\mathrm{p}=0 \cdot 21$.

Table 4: Results of rheumatoid factor in both groups. Results are shown as mean (SD) and range

\begin{tabular}{lllllll}
\hline Group $^{*}$ & Week & & & & \\
\cline { 2 - 6 } & 0 & 4 & 8 & 12 & 16 & 24 \\
\hline 1 & $858(1754)$ & $902(1887)$ & $371(903)$ & $205(458)$ & $170(312)$ & $167(267)$ \\
& $(<60-6516)$ & $(<60-7488)$ & $(<60-3996)$ & $(<60-1960)$ & $(<60-1310)$ & $(<60-1100)$ \\
& $\mathrm{n}=20$ & $\mathrm{n}=19$ & $\mathrm{n}=19$ & $\mathrm{n}=17$ & $\mathrm{n}=16$ & $\mathrm{n}=15$ \\
2 & $633(700)$ & $644(931)$ & $529(659)$ & $306(322)$ & $262(300)$ & $262(309)$ \\
& $(<60-2210)$ & $(<60-3702)$ & $(<60-2250)$ & $(<60-1190)$ & $(<60-1040)$ & $(<60-950)$ \\
& $\mathrm{n}=20$ & $\mathrm{n}=18$ & $\mathrm{n}=19$ & $\mathrm{n}=16$ & $\mathrm{n}=15$ & $\mathrm{n}=13$ \\
\hline
\end{tabular}

"For explanation of groups see table 1 .

For explanation of groups see table 1 .
Average test of significance, group by time $\mathrm{p}=0.334$.

scores between groups 1 and 2 were compared a $p$ value of 0.082 was obtained.

\section{Discussion}

Pulsed methylprednisolone has previously been shown by us and other investigators to produce rapid clinical improvements in patients with active rheumatoid arthritis, ${ }^{3-6}$ though the improvement seems not to be sustained when pulsed methylprednisolone is used as the sole treatment. It has been shown to be associated with an early response (by at least six weeks) to the suppressive agents sulphasalazine and Dpenicillamine. ${ }^{6}$ To date there are few data to assess the efficacy and toxicity of combination pulse methylprednisolone and intramuscular gold $v$ intramuscular gold alone. Anecdotal reports have suggested that intravenous pulse methylprednisolone decreased the efficacy of intramuscular gold treatment started at the time of the intravenous pulse. It has been suggested that the marked anti-inflammatory effects of corticosteroid treatment reduce bioavailability of gold salts to inflammatory cells in the synovium and synovial cavity. A recent paper, however, with limited number of patients, suggests beneficial effects of pulsed methylprednisolone in inducing an early remission before gold treatment becomes effective. ${ }^{7}$

Our data are consistent with our previous initial observations in a small number of patients that pulsed methylprednisolone combined with intramuscular gold treatment gives good symptomatic relief, but the results in this double blind, placebo controlled study just fail to reach a statistically significant level. Steroid treatment did not significantly alter the side effects either, but the numbers were too small for meaningful analysis. Overall, however, we are impressed with the relative lack of significant side effects from pulsed steroid treatment combined with chrysotherapy and the prompt and sustained clinical response. Consequently, we are enrolling further patients into the study in an effort to reach statistically significant conclusions. Furthermore, the knowledge that a large oral pulse of steroids gives similar clinical results to an intravenous pulse ${ }^{8}$ suggests that oral steroid pulsing combined with intramuscular gold will be a useful and convenient therapeutic option in patients with active rheumatoid arthritis.

We gratefully thank Miss B Roylance and Ms D Autio for typing the manuscript and May and Baker Australia Pty and Upjohn the manuscript and May and Baker Australia Pty and Upjohn (Aust) Pty for part financial assistance in performing this study. M D Smith is a recipient of a Neil Hamilton Fairley research
fellowship of the National Health and Medical Research Council fellowship of the National Health and Medical Research Council
of Australia. Ms J Smith provided expert statistical assistance and of Australia. Ms J Smith provided expert statistical assistance and
Mr D Cosh expert pharmaceutical advice, and we thank them for their help.

1 McCarty D J, ed. Arthritis and allied conditions. A textbook of rheumatology. 9th ed. Philadelphia: Lea and Febiger, 1979.

2 Kelley W N, Harris E D Jr, Ruddy S, Sledge C B, eds. Texibook of rheumatology. 1st ed. Philadelphia: Saunders, 1981.

3 Liebling M R, Leib E, McLaughlin K, et al. Pulse methylprednisolone in rheumatoid arthritis. A double-blind methylprednisolone in rheumatoid artiritis. A doub

4 Williams I A, Baylis E M, Shipley M E. A double-blind placebo-controlled trial of methylprednisolone pulse therapy in active rheumatoid disease. Lancet 1982; ii: $237-40$.

5 Smith M D, Bertouch J V, Smith A M, et al. The clinical and immunological effects of pulse methylprednisolone therapy in rheumatoid arthritis. 1 . Clinical effects. $\mathcal{F}$ Rheumato 1988; 15: 229-32.

6 Neumann V, Hopkins R, Dixon J, Watkins A, Bird H, Wright V. Combination therapy with pulsed methylprednisolone in rheumatoid arthritis. Ann Rheum Dis 1985 44: 747-51.

7 Walters M T, Cawley M I D. Combined suppressive drug treatment in severe refactory rheumatoid disease: an analysis of the relative effects of parenteral methylprednisolone, cyclophosphamide and sodium aurothiomalate. Ann Rheum Dis 1988; 47: 924-9.

8 Smith M D, Ahern M J, Roberts-Thomson P J. Pulse steroid therapy in rheumatoid arthritis: Can equivalent doses of ora therapy in reuse similar clinical results to intravenous methyl prednisolone? Ann Rheum Dis 1988; 47: 28-33. 